\title{
Korrigendum
}

\section{zur Printausgabe Heft 51, Seite 227}

In der Printausgabe des Heftes 51 ist im Nachruf auf Franziska Lang das Geburtsjahr fälschlicherweise mit 1950 angegeben. Richtig ist, dass Franziska Lang 1960 geboren und 2009 gestorben ist. Die Redaktion entschuldigt sich. 


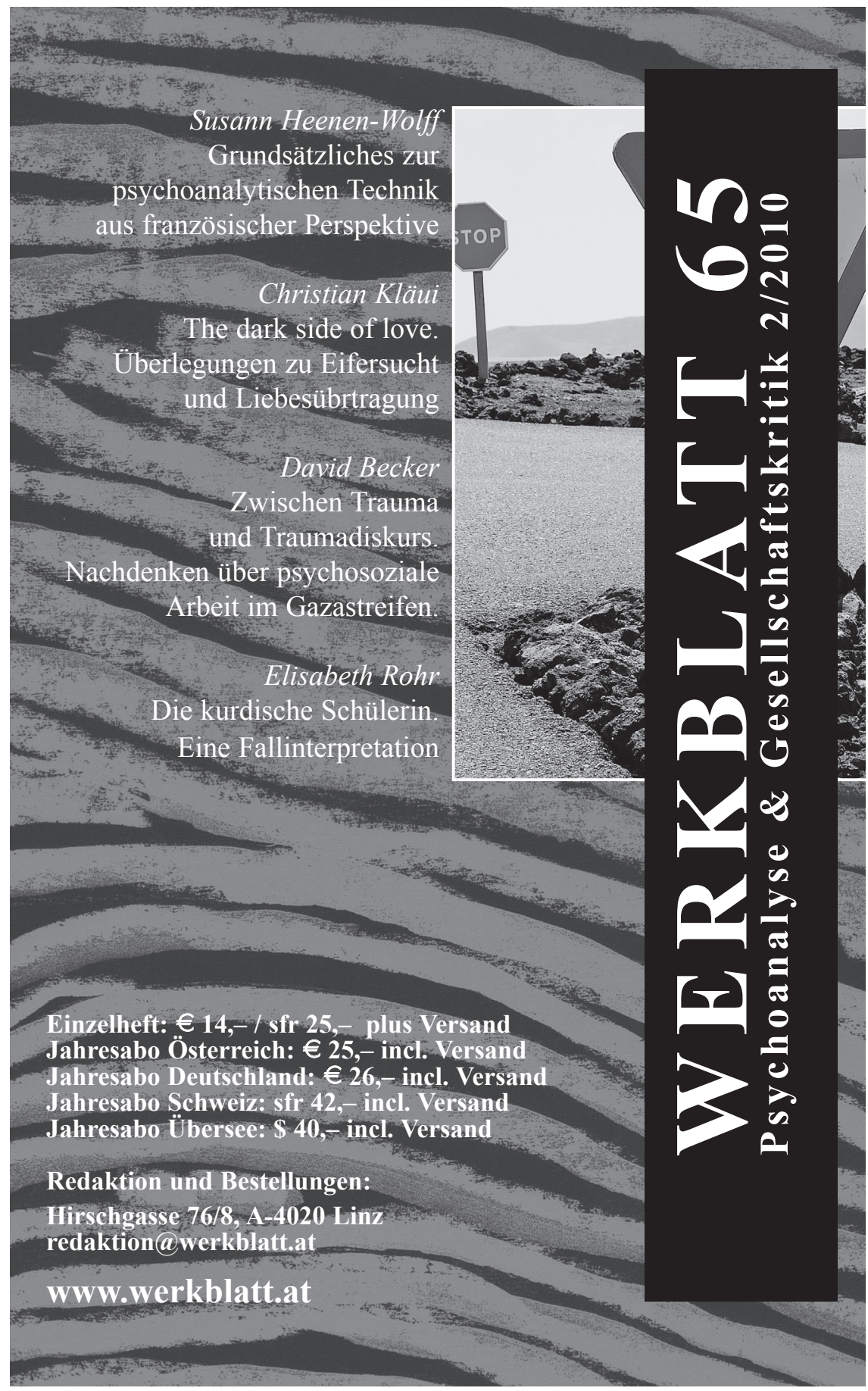


»Niemand führt so diskret, so eindringlich, so umfassend und so wohlinformiert durch die Katakomben der Tiefenpsychologie.«

\section{Peter Sloterdijk}

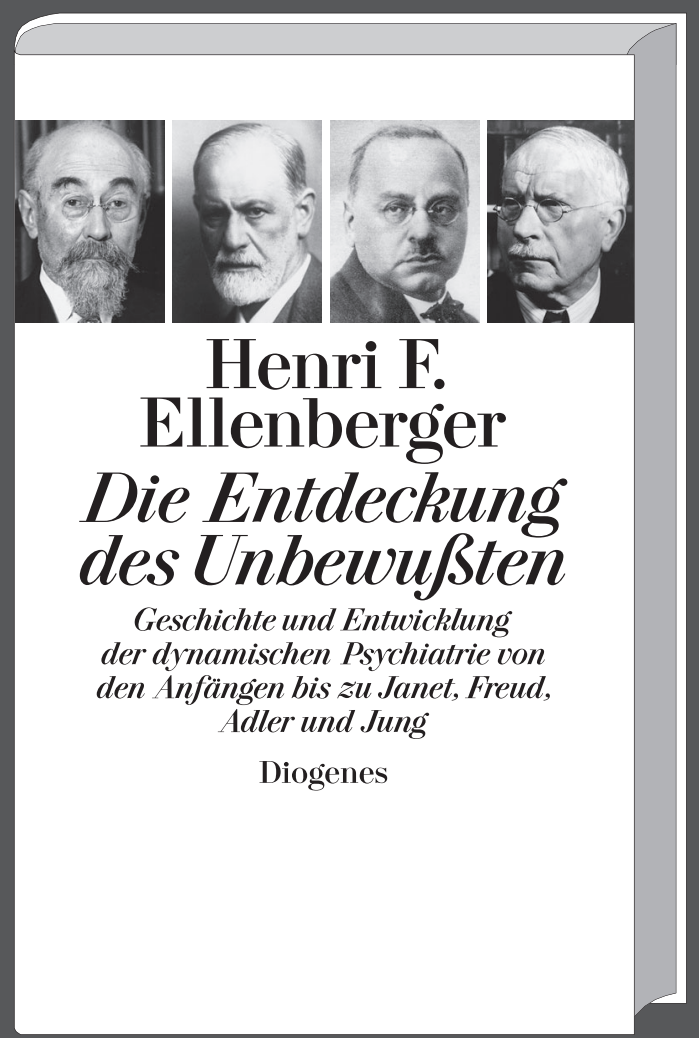

Aus dem Amerikanischen von Gudrun Theusner-Stampa, Mit 45 Abbildungen und Register 1264 Seiten, 12,5 x 20 cm, Leinen, $€$ (D) 36.90 / sFr 63.90* / € (A) 38.-, *unverbindliche Preisempfehlung

Ein Standardwerk - und, das ist ungewöhnlich, ein dazu sehr lesbares und spannendes. Henri F. Ellenberger begnügt sich nicht mit der Darstellung der Lehrsysteme, deren Entwicklung und der Lebensgeschichte der betreffenden Forscher. Durch Betrachtungen über die sozioökonomischen, politischen und kulturellen Faktoren gibt er jeweils ein plastisches Bild von dem Milieu und den Zeitumständen, die die Persönlichkeit der Forscher und ihre Lehren mitgestaltet haben.

\section{Diogenes}




\section{www.klett-cotta.de/fachbuch}

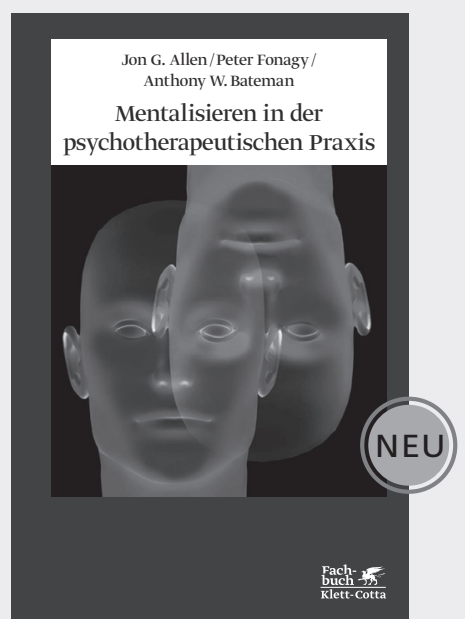

Jon G. Allen / Peter Fonagy /

Anthony W. Bateman

\section{Mentalisieren in der psycho- therapeutischen Praxis}

Aus dem Englischen von

Elisabeth Vorspohl

520 Seiten, gebunden mit

Schutzumschlag

$€ 54,95$ (D) ISBN 978-3-608-94631-4

"Das Buch ist fantastisch gut!"

Ulrich Schultz-Venrath

Allen, Fonagy und Bateman veranschaulichen, was wir heute über das Mentalisierungskonzept wissen und wie wir es anwenden können.

Sie erläutern zunächst die Grundlagen des Konzepts - der Schwerpunkt des Buches liegt jedoch auf der klinischen Anwendung.
Allan N. Schore

Affektregulation und die

Reorganisation des Selbst

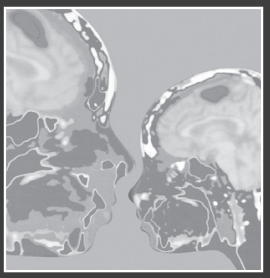

Allan N. Schore

\section{Affektregulation und die Reorganisation des Selbst}

Herausgegeben, mit einem Vorwort versehen und aus dem Amerikanischen übersetzt von Eva Ras

418 Seiten, gebunden mit Schutzumschlag, mit 4 Abbildungen

$€ 39,95$ (D) ISBN 978-3-608-94439-6

„Ein monumentales Werk!»

Peter Fonagy

Schore fügt hier die neuen Ergebnisse der Bindungsforschung und der Hirnforschung zusammen und zeigt, dass es immer mehr Belege dafür gibt, wie gut Freuds Annahmen und unser heutiges Wissen um die Funktionsweise des Gehirns zusammenpassen.

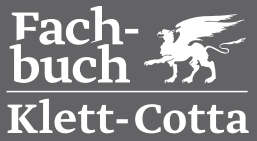



